\author{
Professor Cristina Teodora BĂLĂCEANU, PhD \\ E-mail: movitea@yahoo.com \\ Ministry of National Education \\ Senior Lecturer Mihaela GRUIESCU, PhD \\ E-mail: mgruiescu@yahoo.com \\ The Bucharest University of Economic Studies \\ Senior Lecturer Cristina COCULESCU, PhD \\ E-mail: cristina_coculescu@yahoo.com \\ The Romanian - American University \\ Lecturer Oana Camelia IACOB, PhD \\ E-mail: oanacamelia.i@yahoo.com \\ The Politehnica University of Bucharest
}

\title{
THE ROMANIAN EDUCATIONAL SYSTEM. A CRITICAL ANALYSIS
}

\begin{abstract}
Romania's socio-political context generates a certain degree of ambiguity in all fields, education being one of the most affected areas. The degree of damage is caused by conjuncture-related, economic, psycho-motivational, demographic factors, with varying intensity depending on the background environment and the incidence of societal regression factors (labor migration, decrease in birth rates, and increase in the number of chronic illnesses, school drop-out, increasing functional illiteracy, lowering the overall level of well-being caused by the drop in income).

Keywords:educational environment, school drop-out, sustainable economic development.

\section{JEL Classification: I25, I26}

\section{Introduction}

Consequently, the educational environment in Romania must be correlated with the labor market, both from the perspective of the curriculum (the formation of competencies that are necessary for the fulfillment of converging functions with the current work environment, with an impetus to the information and communication technology), as well as from the perspective of employers' demands for occupations, seen from a dynamic and structural point of view (the offer of specializations of the high-school and university education system will be linked to the job offer within a specific market depending on the potential investments of a particular area, set in the Territorial Development Plan of a region) [China Remus et all, (2014)]. The analysis of the educational system in Romania at the pre-university level takes into account the main deficiencies
\end{abstract}


leading to a small percentage of pupils who pass the baccalaureate exam, early school leaving, but also to the failure of public policies in the field of education. Although the Romanian school is a value-centered school, as confirmed by the large number of Olympics and laureates of national and international school competitions and contests, the newly created value these pupils bring to the educational system in Romania is very low compared to the mass results of the whole educational system as a whole. Another aspect of secondary education is the lack of adaptability to labor market requirements as a result of the lack of qualification of students in relation to the skills demanded by employers, in consensus with the evolution of the knowledge-based economy or the enrollment of pupils in other university education systems outside Romania. Another issue is the increase in poverty-related abandonment or social problems within the community that cannot be resolved under current budget allocation.

At the same time, the impressive results of pupils at school level require an analysis to determine whether they are an effect of the curriculum, of the ordinary learning environment in the Romanian school classes, or are the concentrated effect of student-teacher teams focused on the subject and the results are generated exclusively from this effort.

The high level of school dropout combined with the high rate of functional illiteracy determined by PISA tests adds new concerns to the phenomenon of demographic aging in Romania. The decline in the birth rate and the migration of the young and skilled labor force will be accompanied by another phenomenon: a significant percentage of the young population will not only have poor education and a very low adaptability to the labor market requirements, thus low contributions to the GDP, but they will also generate new pressures on social assistance costs (about one in five students in Romania reaches a maximum of eight grades).

\section{Materials and Methods}

The objective of our research is to identify a relationship between the degree of dropout and sustainable economic growth. We believe that poverty is perpetuating in certain areas of Romania as a result of a combination of factors including lack of investment, poor policy approaches, increasing school dropout, increasing the incidence of poverty in social delinquency. In order to increase the success of educational policies, it is necessary to increase the financing of the education system as a whole, through sustainable investments and attracting the business environment in support of educational programs with a high applicative content [Rodriguez-Pose, A. and E. Garcilazo, (2015)], but also the empowerment of teachers and institutional decision-makers in promoting values and principles centered on pupils and their educational path [OECD, (2011)] in line with the requirements of a modern, changing society, oriented towards competitiveness and inclusive growth [European Comision, (2009)]. 
The Romanian Educational System. A Critical Analysis

In this paper, we propose the pursuit of two objectives, as follows:

Objective 1- identifying a correlation between abandonment rate and GDP growth

Objective 2 - identifying an objective function to stimulate participation of young people in the compulsory education system

The two objectives contribute to identifying the state of education in Romania in terms of the effectiveness of public policies. At the same times, identifying the factors that can reduce the causes of abandonment contribute to the setting of the prerequisites for action to reduce the school dropout rate.

\section{Results}

\subsection{The analysis of the dropout rate within the Romanian educational} system

From the analysis of the presented data, there is a considerable link between the level of abandonment and the degree of performance of the economy, as measured by the economic growth and the increase of the wage level. The higher the social impact of public policies on the income level of the population, the more the interest in education will increase. Romania has to recover a whole period when public policies were minimal, contributing only to ensuring short-term and very short-term subsistence income. Investments in service infrastructure, including education, have been postponed in several economic cycles, which have led to increased levels of social exclusion through high school abandonment, insufficient income to train the skills required to join in a consumer society where the main feature is competitiveness.

Although it is desirable to change the optics of the education system in consensus with the technology of the future, in economies where societal differences are increasingly acute, characterized by urban-rural dichotomy, wages depending on the incidence of the field of activity on the market, excessive trade liberalization and choice of investment based on the opportunity cost of using economic resources, education must remain a fundamental, inalienable and offmarket right.

The right to education is a constitutional right, but it is not guaranteed in Romania, because it does not guarantee the income of families whose children are at risk of poverty and school dropout. The conclusion of the paper present a direct link between the right to education through participation in the educational system only for those families who have a certain income necessary to ensure the minimum conditions for attending the school. The allocation of social assistance at local level to those communities where there are high levels of school dropout rates contributes to the reduction of causes but also creates the preconditions for integration into support programs to increase long-term subsistence capacity at market rigidities.

Highlighting the positive results of the Romanian school is an essential aspect of the competition in the educational market, compared to other countries in Europe or the world. The degree of internationalization that the Romanian school is trying, voluntarily or as a consequence of these exceptional results, would place 
the Romanian school in terms of comparative advantage in a leading position in the top-ranked schools in the world, which could attract pupils from other countries through related programs at schools in Romania. The strategy of the Romanian school should take into account the internationalization in order to go beyond the values pyramid, the effect of an individual learning program centered on achieving remarkable results at an individual level [Gaspar Florentina, (2018)]. This is not the rule of the Romanian school, but only the exception.

The analysis of the education system as a whole seeks to identify those elements that would trigger in time sustainable effects in the welfare plan of the Romanian population, identified in the real plan, the increase in the supply of jobs, the increase of the average salary in the economy, the improvement of the daily basket, increasing the production with new value created in Romania by the graduates of the education system in Romania.

The research envisages the explanation of why the level of education in Romania could be raised as a result of changes in strategy in student-centered education policy, increasing the number of practical training hours, exchanging good practice with other countries with some European programs.

For backing the support of this assumption we consider the results obtained by Romania in the international tests for assessment of general competences specific to a certain age group. Thus, in PISA testing in 2015, 5,103 Romanian pupils aged between 15 years and 3 months and 16 years and 2 months at the time of testing in 185 schools were assessed on three areas: Natural Sciences, Mathematics and Reading / Reading to solve structured topics in two hours. The sampling of schools and pupils is done externally by the PISA Consortium using dedicated software. It can be noticed that Romanian pupils have lower scores than other countries, especially literacy and literacy skills. PISA data allows estimating the proportions of students who are functionally illiterate or who face severe difficulties in understanding written texts of low difficulty. According to PISA 2015, 42\% of 15year-olds in Romania are in this category, growing 5\% from 2012 [PISA (2015) Results (Volume II)]. Romania's score on Sciences, the focus area on the latest tests, is 435 against the average score of the OECD countries, 493, and the best score, that of Singapore students, which was 558. On the Reading side, Romania gained 434 points, compared to the OECD average score of 493 points, and for Mathematics 444 points, compared to the OECD average score of 490 [PISA (2015) Results (Volume III)]. If these students graduate from pre-university education, they will have difficulties at work and in everyday life in the performance of activities with an average degree of understanding of tasks requiring interpretation of the law, obtaining positions or qualities through the competition, the contracting of credits or the use of products with a high degree of digitization, the ability to make decisions on the participation of some people in public life (understanding the political concepts, the implications of voting by politicians). 
The Romanian Educational System. A Critical Analysis

\subsection{Analysis of the causes that determine the poor results of the Romanian educational system}

The system of public policies in Romania captures the structural changes taking place within society, determined in general by phenomena such as (1) the migration of a significant part of the labor force to economies characterized by sustainable rates of economic growth, (2) low participation of the urban and middle-aged population in the capacity of parties in power to contribute to increasing social welfare, (3) reduced capacity of the public expenditure support economy through the mechanism of redistribution of public revenues, which leads to an increase in the budget deficit, with effects on the financial macro-stability [Gengyuan Liu, Mark T. Brown, Marco Casazza, (2017)]. The consequence of the lack of efficient governance of the national economy is the proliferation of unsustainable public policies, especially in the field of continuous education and training. We believe that the causes that lead to these poor results are:

$\checkmark$ Applying a curriculum focused on large amounts of weak or inadequately structured information. This curriculum, instead of developing students' creativity and critical thinking, primarily aims to develop a single cognitive function: memorizing;

$\checkmark$ The curriculum of the different disciplines has no interdisciplinary character and has not been built from the perspective of a synergistic vision;

$\checkmark$ Teaching methods focus largely on the transmission of information and the verification of its memorization. We believe that intensive teaching and learning methods should be promoted and exploited: group projects, learning by discovery;

$\checkmark$ Excessive and continuous loading of the curriculum leads to the perpetuation of failure in the learning process of students who have not kept up with the requirements of the first years of schooling. Those students will find it increasingly difficult to recover their learning outcomes, which may cause them to drop out of school;

$\checkmark$ Having the curriculum of all disciplines at the level of each school year involves creating a highly loaded work program for students who comply with all of their requirements, and, worse, makes it necessary to prepare them outside of school hours by tutoring. In this context, not only the free time of students is affected to the detriment of extracurricular activities, but tutoring involves also the financial effort of the parents, and the school performances of a student may depend on the financial strength of his family;

$\checkmark$ Lack of motivation of students in relation to the curriculum as a result of external stimuli that greatly disrupt the ability to concentrate on didactic activities (activating social networks, using phones and other gadgets during classes, when it is not allowed or when it does not confer a teaching support for the lesson); 


\section{Cristina Bălăceanu, Mihaela Gruiescu, Cristina Coculescu, Oana Camelia Iacob}

$\checkmark$ The lack of parents' involvement in the teaching process towards the exercise of control or the imposition of limits on behavior in the school (includes clothing, vocabulary, ethical behavior, respect, tolerance);

$\checkmark$ Lack of means of monitoring and measuring the pupils' activity on the acquisition of knowledge in the form of interdisciplinary tests with applicative character, with a high degree of relevance in relation to the requirements of the society based on advanced knowledge, cutting edge technologies and digitization;

$\checkmark$ Relevance of educational policy within school community.

Another defining aspect of the low capacity of the Romanian educational system to cope with high competition in the labor market is passing the baccalaureate exam. This has the most negative results, both in the psychosocial plan (lack of motivation, increasing the level of social exclusion on the labor market, engaging in seasonal activities at the limit of the law or outside it) and also at the economic level by lowering the average wage level on the market by increasing the incidence on the labor market of people with inadequate training who accept low pay levels only to ensure a minimum level of subsistence, lower investor interest in business development in economic regions where labor is unskilled or productive of low work.

The data presented in Figure 1 are caused by a cumulating of factors related to the internal problems of the educational system on the one hand and by the lack of convergence between the educational system and the labor market. The low number of pupils who pass the baccalaureate exam shows a lack of involvement in the educational act of students, either from structural causes (the curriculum not adapted to pupils' requirements or understanding abilities, class size, high number of study subjects with a sufficient number of hours for teaching and training pupils, lack of an inadequate scoring system), or lack of pupils' motivation in relation to the future prospects that can be promoted by passing the baccalaureate.

The system should generate solutions based on an objective, SMART-type analysis within each school unit. Based on an objective function, it is possible to corroborate types of measures that solve a common problem for several types of school units. This type of solution contributes to the efficient use of public money and the adaptability of public policy measures according to the specifics of the problem, the characteristics of the school population, the need for labor resources at the regional level, the needs of the labor market. 
Figure 1. Graduation rate for the baccalauréat exam

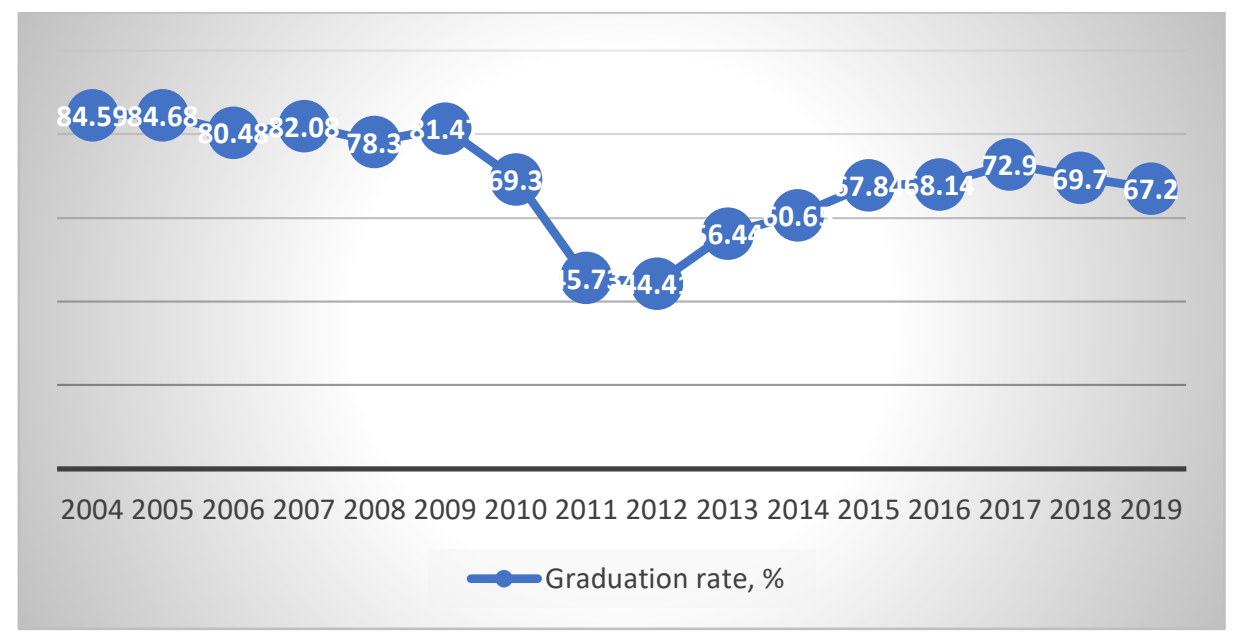

Source-processed using data from www.edu.ro

Among the causes, we can also identify internal issues related to public policy management in the educational field, such as applying a mix of strategies that do not have a common co-ordination base at the application level. Thus, preuniversity education units based on competence analysis, in conjunction with needs analysis, could manage educational resources in order to adapt long-term educational requirements from the perspective of accountability, critical analysis, decision-making in risk and uncertainty. The educational policies lack flexibility and operationally, on the one hand, but also links to school realities. Thus, the application of identical programs for different types of problems attracts the lack of efficient use of public money, but also the achievement of learning outcomes that do not correspond to the indicators pursued for the achievement of performance criteria.

We believe that the level of involvement of public policies at school level must be correlated with the medium and long-term growth prospects of the economy [Breinlich et all. (2015)]. The school forms labor resources for the future, with competencies that meet the future demands of the labor market and society in general, which can be prefigured on the basis of development strategies at regional level.

In recent years, Romania has made progress in reducing macroeconomic imbalances that have not been sufficient to reduce poverty and social exclusion, downwards compared to 2015, but insufficient to reduce dropout in education and early school leaving in Romania. Thus, concerted measures are required for the sustainability of initial, continuous and targeted education and training systems 
offered in different ways but leading to immediate effects in terms of school population growth and poverty reduction, especially in rural areas.

Among the measures that have been undertaken within the education system, three functional dimensions of policies and institutions are being identified in cooperation with the World Bank in the framework of the "Systemic Approach to Improve Educational Outcomes - Labor Force Development", thus:

$\checkmark$ Actions to support the policy level, partnership and trans-sectorial coordination, aimed at aligning the workforce in critical areas of national development priorities;

$\checkmark$ Measures which govern funding, quality assurance and learning paths by determining incentives and information that influences the choices of students, employers, training providers, other stakeholders;

$\checkmark$ Diversity, organization and management of the training offer which ensures practical results, giving participants the opportunity to acquire the required skills on the labor market and at the workplace.

By implementing these measures, the Romanian school is flexible and offers the young generations' impetus to the increase of the interest for learning in the context in which the labor market will absorb the workforce so formed.

If the school currently offers poorly trained young people with low incidence of absorption, even in unskilled work, the level of poverty, delinquency and social exclusion will increase. All this leads to the polarization of society without chances of sustainable labor integration in advanced labor market systems.

A secondary effect of poverty is also the drop in the number of pupils, whether due to demographic causes or abandonment. School abandonment can be determined by a weak link between the labor market and the education system, on the one hand, or a poor motivation for the educational act stemming from the lack of social models.

In Romania, for particularly social reasons, school dropout is particularly high, especially in regions where there are a number of factors of a multiple nature: poverty, lack of jobs, and lack of investment, poor business infrastructure, and migration of labor able to prosperous economic territories, lack of propensity to education at family level, ethnic group, and community. At the same time, the power of the example prevails within community, the influence of the leader, the business success rate of those who graduated school under onerous conditions.

We believe that future studies will be needed to monitor the progress of each promotion, from the beginning to the end of studies. For example, in 2007, about 230,000 students entered the pre-university school system, and in the 12th grade, completed in 2019, they reached about 100,000 less. At the baccalaureate exam between June and July 2019, 129,197 pupils enrolled and 89,215 students passed, which strengthens the failure of educational policies to increase pupils' performance and motivation by facilitating learning through modern teaching 
The Romanian Educational System. A Critical Analysis

methods, but also increasing the level of responsibility of pupils throughout their school years [SABER, (2017)].

The Analysis of the evolution of the 2007-2019 generation is of particular relevance and because in 2015, as a result of PISA testing, $40 \%$ of the 15-year-old students tested is characterized by functional illiteracy. Also, only 158,568 pupils were enrolled in the national evaluation in 2015, of which 125,782 pupils obtained averages over 5 [Vlaston Stefan, (2015)].

By extrapolating, if each promotion "loses" about 100,000 students from the beginning to the end of studies, i.e. over $40 \%$ of its potential, studies are needed to assess the impact of school abandon on the labor force structure for each decade and the implications of education system failures on the long-term evolution of Romania.

\section{Discussion}

Starting from the data series in Figure no. 2 on the School Abandonment Rate in Romania during 2001-2017, we will try to determine the most appropriate curve for adjusting the evolution of this indicator, and with the help of the adjustment function we will try to make a forecast on the evolution of the dropout rate in Romania for the period 2018-2020.

The evolution graph of the analyzed indicator entitles us to assume that its econometric description can be achieved by means of a polynomial model [Andrei, T. (2004)].

Figure 2. Evolution of the dropout rate in Romania during 2001-2017

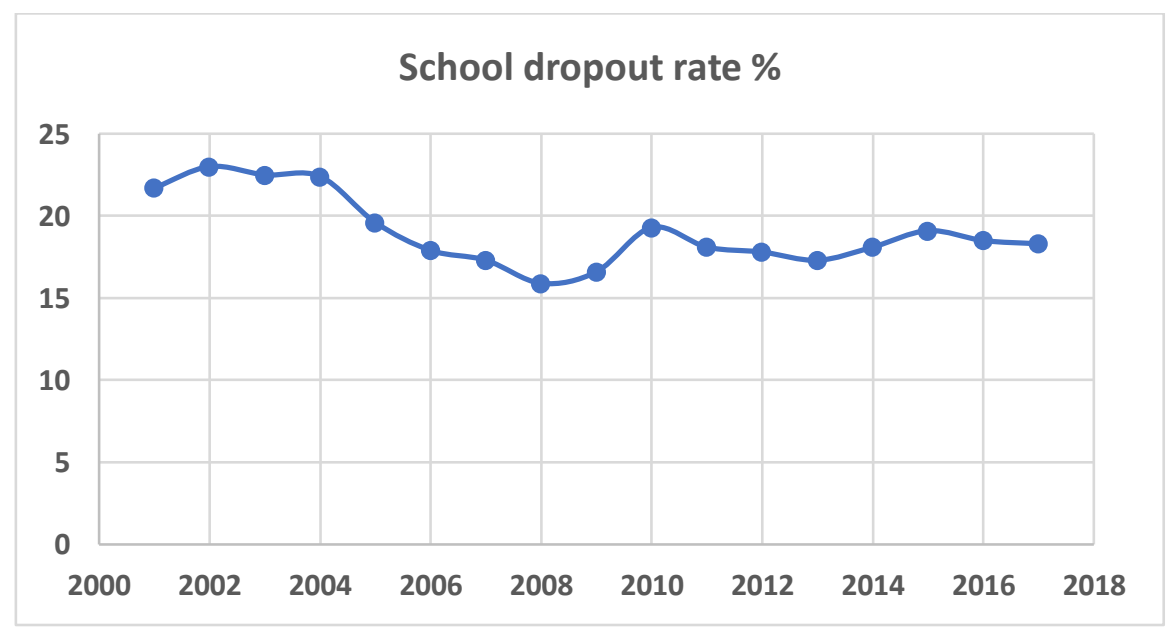

Source: Own authors' contribution based on www.edu.gov.ro 
Cristina Bălăceanu, Mihaela Gruiescu, Cristina Coculescu, Oana Camelia Iacob

To choose the mathematical function that properly describes the process, we will use the computational support provided by the specialized packages in MATLAB [Enders, W. (1995)].

Linear model Poly4: $\mathrm{P} 4(\mathrm{x})=\mathrm{p} 1 * \mathrm{x}^{\wedge} 4+\mathrm{p} 2 * \mathrm{x}^{\wedge} 3+\mathrm{p} 3 * \mathrm{x}^{\wedge} 2+\mathrm{p} 4 * \mathrm{x}+\mathrm{p} 5$

Coefficients (with $95 \%$ confidence bounds):

$$
\begin{aligned}
& \text { p1 }=-0.00235 \quad(-0.004437,-0.0002621) \\
& \text { p2 }=18.88 \quad(2.106,35.65) \\
& \text { p3 }=-5.688 \mathrm{e}+004 \quad(-1.074 \mathrm{e}+005,-6348) \\
& \text { p4 }=7.616 \mathrm{e}+007 \quad(8.503 \mathrm{e}+006,1.438 \mathrm{e}+008) \\
& \text { p5 }=-3.824 \mathrm{e}+010 \quad(-7.222 \mathrm{e}+010,-4.271 \mathrm{e}+009)
\end{aligned}
$$

Goodness of fit: SSE: 13.68; R-square: 0.813; Adjusted R-square: 0.7451; RMSE: 1.115

Figure 3. Grade 4 polynomial regression model and prediction interval

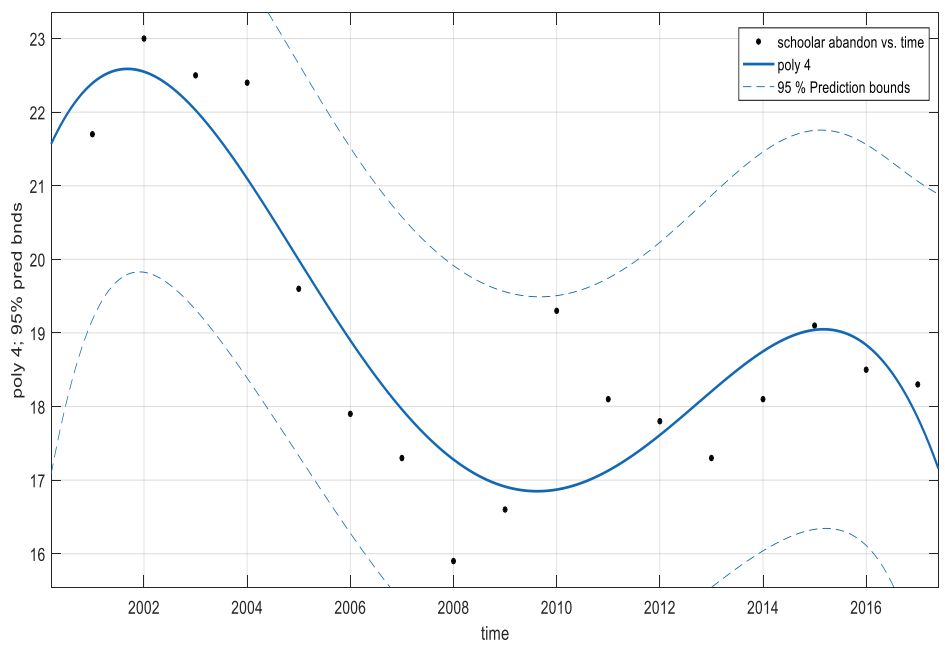

Source: Own authors' contribution p6

Linear model Poly5: P5(x) $=\mathrm{p} 1{ }^{*} \mathrm{x}^{\wedge} 5+\mathrm{p} 2{ }^{*} \mathrm{x}^{\wedge} 4+\mathrm{p} 33^{*} \mathrm{x}^{\wedge} 3+\mathrm{p} 4{ }^{*} \mathrm{x}^{\wedge} 2+\mathrm{p} 5 * \mathrm{x}+$

Coefficients (with $95 \%$ confidence bounds):

$$
\begin{aligned}
& \text { p1 }=0.0005168 \quad(6.546 \mathrm{e}-005,0.0009682) \\
& \text { p2 }=-5.192 \quad(-9.725,-0.6597) \\
& \text { p3 }=2.087 \mathrm{e}+004 \quad(2659,3.908 \mathrm{e}+004) \\
& \text { p4 }=-4.193 \mathrm{e}+007 \quad(-7.85 \mathrm{e}+007,-5.361 \mathrm{e}+006) \\
& \text { p5 }=4.213 \mathrm{e}+010 \quad(5.402 \mathrm{e}+009,7.885 \mathrm{e}+010) \\
& \text { p6 }=-1.693 \mathrm{e}+013 \quad(-3.168 \mathrm{e}+013,-2.178 \mathrm{e}+012)
\end{aligned}
$$

Goodness of fit: SSE: 8.301; R-square: 0.8865; Adjusted R-square: 0.8298; RMSE: 0.9111 
The Romanian Educational System. A Critical Analysis

Figure 4. Grade 5 polynomial regression model and prediction intervals

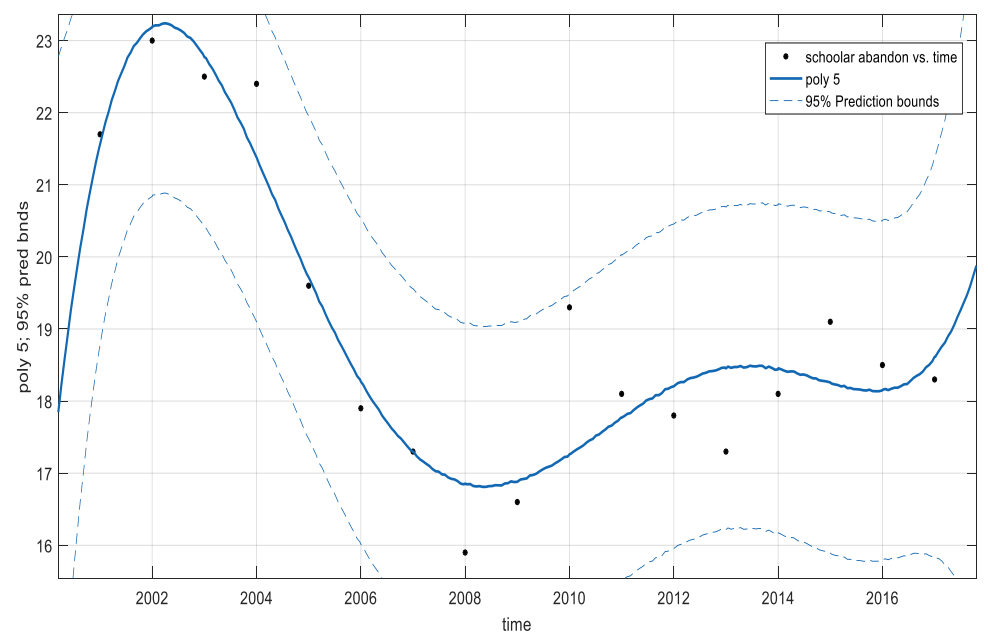

Source: Own authors' contribution

Table 1. The adjusted school dropout rate

\begin{tabular}{|c|c|c|c|c|c|c|c|}
\hline $\boldsymbol{x}_{\boldsymbol{i}}$ & $\boldsymbol{P}_{\mathbf{5}}\left(\boldsymbol{x}_{\boldsymbol{i}}\right)$ & $\boldsymbol{x}_{\boldsymbol{i}}$ & $\boldsymbol{P}_{\mathbf{5}}\left(\boldsymbol{x}_{\boldsymbol{i}}\right)$ & $\boldsymbol{x}_{\boldsymbol{i}}$ & $\boldsymbol{P}_{\mathbf{5}}\left(\boldsymbol{x}_{\boldsymbol{i}}\right)$ & $\boldsymbol{x}_{\boldsymbol{i}}$ & $\boldsymbol{P}_{\mathbf{5}}\left(\boldsymbol{x}_{\boldsymbol{i}}\right)$ \\
\hline \hline 2001 & 21.5586 & 2006 & 18.2695 & 2011 & 17.7695 & 2016 & 18.1543 \\
2002 & 23.1855 & 2007 & 17.2988 & 2012 & 18.2051 & 2017 & 18.6133 \\
2003 & 22.7715 & 2008 & 16.8555 & 2013 & 18.4531 & 2018 & 20.3828 \\
2004 & 21.3828 & 2009 & 16.8809 & 2014 & 18.4395 & 2019 & 24.5293 \\
2005 & 19.7168 & 2010 & 17.2617 & 2015 & 18.2578 & 2020 & 32.4902 \\
\hline
\end{tabular}

Source: Own authors contribution from www.edu.gov.ro

Linear model Poly6: P6(x) $=\mathrm{p} 1{ }^{*} \mathrm{x}^{\wedge} 6+\mathrm{p} 2{ }^{*} \mathrm{x}^{\wedge} 5+\mathrm{p} 3{ }^{*} \mathrm{x}^{\wedge} 4+\mathrm{p} 4{ }^{*} \mathrm{x}^{\wedge} 3+\mathrm{p} 5{ }^{*} \mathrm{x}^{\wedge} 2$ $+\mathrm{p} 6 * \mathrm{x}+\mathrm{p} 7$

Coefficients (with $95 \%$ confidence bounds):

$$
\begin{aligned}
& \text { p1 }=-1.157 \mathrm{e}-006(-9.264 \mathrm{e}-006,6.95 \mathrm{e}-006) \\
& \text { p2 }=0.01452(-0.08354,0.1126) \\
& \text { p3 }=-75.8(-570.1,418.5) \\
& \text { p4 }=2.107 \mathrm{e}+005(-1.118 \mathrm{e}+006,1.539 \mathrm{e}+006) \\
& \text { p5 }=-3.291 \mathrm{e}+008(-2.338 \mathrm{e}+009,1.68 \mathrm{e}+009) \\
& \text { p6 }=2.738 \mathrm{e}+011(-1.347 \mathrm{e}+012,1.894 \mathrm{e}+012) \\
& \text { p7 }=-9.481 \mathrm{e}+013(-6.394 \mathrm{e}+014,4.498 \mathrm{e}+014)
\end{aligned}
$$

Goodness of fit: SSE: 11.36; R-square: 0.8447; Adjusted R-square: 0.7411; RMSE: 1.124 
Figure 5. Grade 6 polynomial regression model and prediction interval

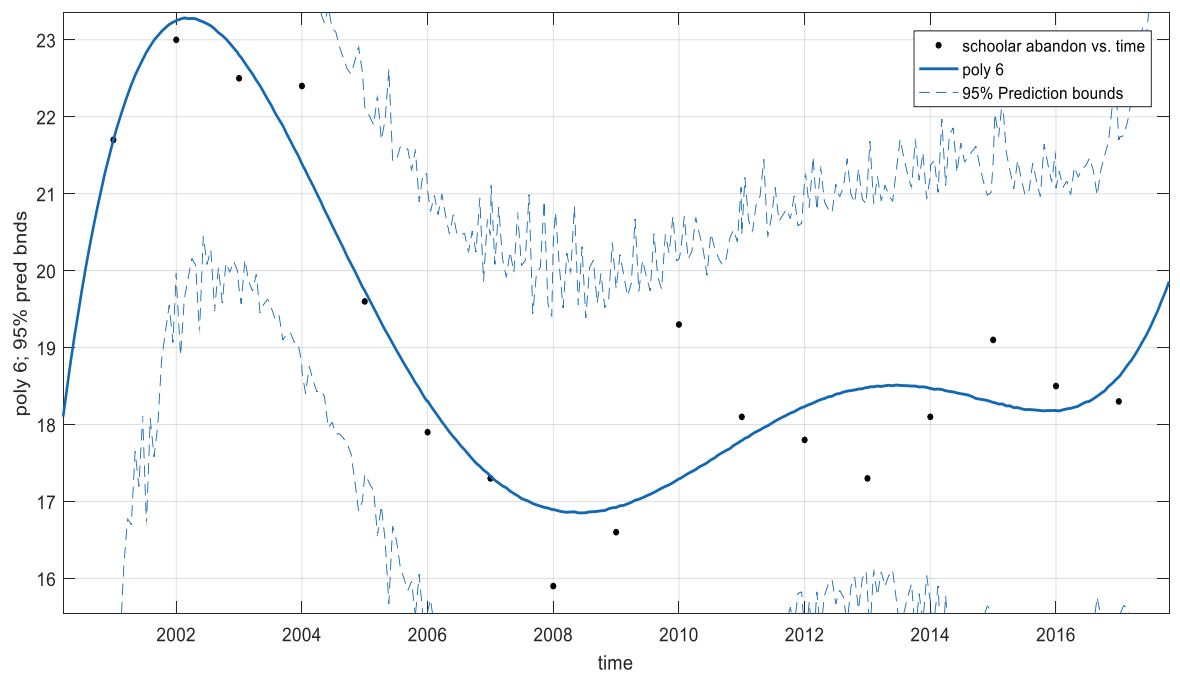

Source: Own authors' contribution

In figures no. 3, 4 and 5 three types of curves are observed: the empirical curve of the data, represented by the points, the gradient of the 4th, 5th and 6th grade regression polynomials of the smallest squares corresponding to the data represented by the continuous line and the two curves signify the confidence interval for prediction, represented by dotted curves [Bobko et all., (2005)].

Analyzing the regression statistics obtained according to the polynomial models used to adjust the data series, we can conclude that the model that has the most optimal statistics [Coculescu, C., Despa, R., (2011)] (the smallest sum of residual squares and the smallest standard error, respectively, the highest specific correlation coefficient and the highest adjusted coefficient), is the grade 5 polynomial [Gujarati, D.N. (1995)].

In the following, as we have identified the factors that maintain the school abandonment status, we will analyze the dependence between the dropout rate in Romania and factors of influence such as: GDP, population, annual average wage. For this we will use a multiple, linear regression model between:

Dependent variable Y - dropout rate (\%) and

Variables X1-GDP growth rate per inhabitant (\%),

$\mathrm{X} 2$ - annual net average wage (thousand lei / employee) of the following form:

$\mathrm{Y}=\llbracket \mathrm{b} \_0+\mathrm{b} \rrbracket \_1 \mathrm{X} \_1+\mathrm{b} \_2 \mathrm{X} \_2+\varepsilon$.

The study of the behavior of the effect $Y$ variable in relation to the influence factors $\mathrm{X} 1, \mathrm{X} 2$ goes to the evaluation of the regression parameters $\mathrm{b} 0, \mathrm{~b} 1, \mathrm{~b} 2$. 
The Romanian Educational System. A Critical Analysis

Estimation of the regression coefficients will be based on a sample of data on the indicators considered in the model, for Romania, during 2001-2017.

Table 2. The values of the three variables in the RPS matrix

\begin{tabular}{|c|c|c|c|}
\hline Year $(t)$ & $\begin{array}{l}X_{1-G D P} \\
\text { Growth rate per } \\
\text { capita }(\%)\end{array}$ & $\begin{array}{l}X_{2} \text {-Annual average } \\
\text { wage, Romanian } \\
\text { currency, lei }\end{array}$ & $\begin{array}{lr}\mathbf{Y}- & \text { School } \\
\text { dropout } & \text { rate } \\
(\%) & \end{array}$ \\
\hline 2001 & 7.076 & 3053.598 & 21.7 \\
\hline 2002 & 7.127 & 3881.178 & 23 \\
\hline 2003 & 6.288 & 4868.104 & 22.5 \\
\hline 2004 & 8.978 & 5965.285 & 22.4 \\
\hline 2005 & 4.817 & 0.738 & 19.6 \\
\hline 2006 & 8.698 & 0.862 & 17.9 \\
\hline 2007 & 8.454 & 1.036 & 17.3 \\
\hline 2008 & 10.281 & 1.282 & 15.9 \\
\hline 2009 & -6.289 & 1.381 & 16.6 \\
\hline 2010 & -0.207 & 1.407 & 19.3 \\
\hline 2011 & 1.555 & 1.475 & 18.1 \\
\hline 2012 & 1.09 & 1.547 & 17.8 \\
\hline 2013 & 3.917 & 1.622 & 17.3 \\
\hline 2014 & 3.463 & 1.706 & 18.1 \\
\hline 2015 & 4.153 & 1.848 & 19.1 \\
\hline 2016 & 4.8 & 2.088 & 18.5 \\
\hline 2017 & 7.076 & 2.384 & 18.3 \\
\hline
\end{tabular}

Source: *) World Bank national accounts data, and OECD National Accounts data files.

**) processed by www.insse.ro/cms/ro/content/castiguri-salariale

To begin with, we will consider the data stored in the matrix RPS in MATLAB.

\begin{tabular}{|c|c|c|c|c|c|c|}
\hline \multicolumn{3}{|c|}{$\gg$ RPS $=[7.076$} & \multirow[t]{2}{*}{3053.598} & \multicolumn{3}{|c|}{$\mathrm{RPS}=1.0 \mathrm{e}+03 *$} \\
\hline & 21.7 & & & 0.0071 & 3.0536 & 0.0217 \\
\hline 7.127 & 3881.17 & & 23 & 0.0071 & 3.8812 & 0.0230 \\
\hline 6.288 & 4868.10 & & 22.5 & 0.0063 & 4.8681 & 0.0225 \\
\hline 8.978 & 5965.28 & & 22.4 & 0.0090 & 5.9653 & 0.0224 \\
\hline 4.817 & 0.738 & 19.6 & & 0.0048 & 0.0007 & 0.0196 \\
\hline 8.698 & 0.862 & 17.9 & & 0.0087 & 0.0009 & 0.0179 \\
\hline 8.454 & 1.036 & 17.3 & & 0.0085 & 0.0010 & 0.0173 \\
\hline 10.281 & 1.282 & 15.9 & & 0.0103 & 0.0013 & 0.0159 \\
\hline-6.289 & 1.381 & 16.6 & & -0.0063 & 0.0014 & 0.0166 \\
\hline-0.207 & 1.407 & 19.3 & & -0.0002 & 0.0014 & 0.0193 \\
\hline 1.555 & 1.475 & 18.1 & & 0.0016 & 0.0015 & 0.0181 \\
\hline 1.09 & 1.547 & 17.8 & & 0.0011 & 0.0015 & 0.0178 \\
\hline
\end{tabular}


Cristina Bălăceanu, Mihaela Gruiescu, Cristina Coculescu, Oana Camelia Iacob

\begin{tabular}{|lll|lll|}
\hline 3.917 & 1.622 & 17.3 & 0.0039 & 0.0016 & 0.0173 \\
3.463 & 1.706 & 18.1 & 0.0035 & 0.0017 & 0.0181 \\
4.153 & 1.848 & 19.1 & 0.0042 & 0.0018 & 0.0191 \\
4.8 & 2.088 & 18.5 & 0.0048 & 0.0021 & 0.0185 \\
7.076 & 2.384 & 18.3 & 0.0071 & 0.0024 & 0.0183 \\
\hline
\end{tabular}

By calling the regress function in the Statistics Toolbox [Anderson, Sweeney, Williams, (2008)], we will obtain the multiple regression model parameters along with the reliable intervals. It can also return as a result the residue row along with reliable intervals and a few statistics that give the quality of regression [Pecican, E.Ş., (2003)].

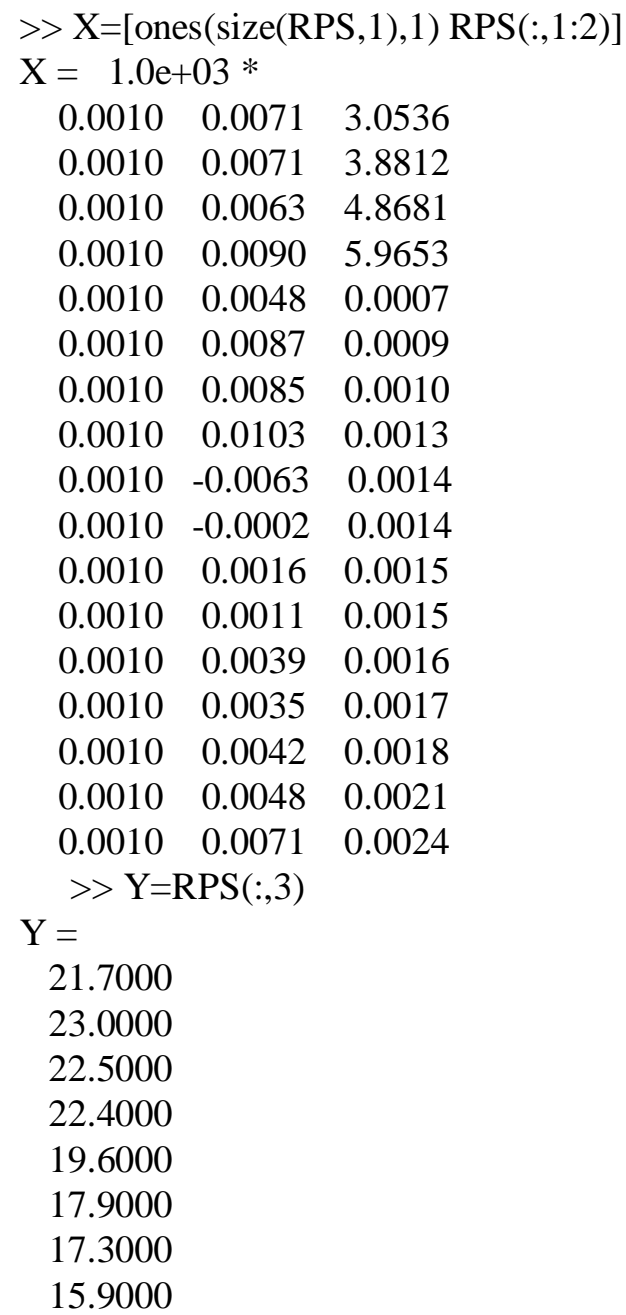


The Romanian Educational System. A Critical Analysis
16.6000
19.3000
18.1000
17.8000
17.3000
18.1000
19.1000
18.5000
18.3000
> $[\mathrm{b}$, bint,, ,rint, stats $]=\operatorname{regress}(\mathrm{Y}, \mathrm{X})$

For data in the RPS matrix, we obtain:

In the output parameter $\mathrm{b}$ the regression coefficients are stored, the order corresponding to the columns $\mathrm{X}$ in the matrix, i.e. the first value in $\mathrm{b}$ is the free term, the second value is the coefficient of the first factor $\mathrm{X} 1$ and the third value in $\mathrm{b}$ is the coefficient of $\mathrm{X} 2$ :

$$
\mathrm{b}=18.1212-0.0183 \quad 0.0009
$$

Therefore:

$$
\mathrm{Y}=18.1212-0.0183 \cdot \mathrm{X} \_1+0.0009 \llbracket \cdot \mathrm{X} \rrbracket \_2+\varepsilon
$$

bint stores the ends of the reliable intervals corresponding to the regression parameters:

$$
\begin{array}{rcc}
\text { bint }= & 17.2210 & 19.0213 \\
-0.1734 & 0.1369 \\
0.0006 & 0.0013
\end{array}
$$

In $\mathrm{r}$, respectively rint is stored the residue vector and the reliable intervals for residues:

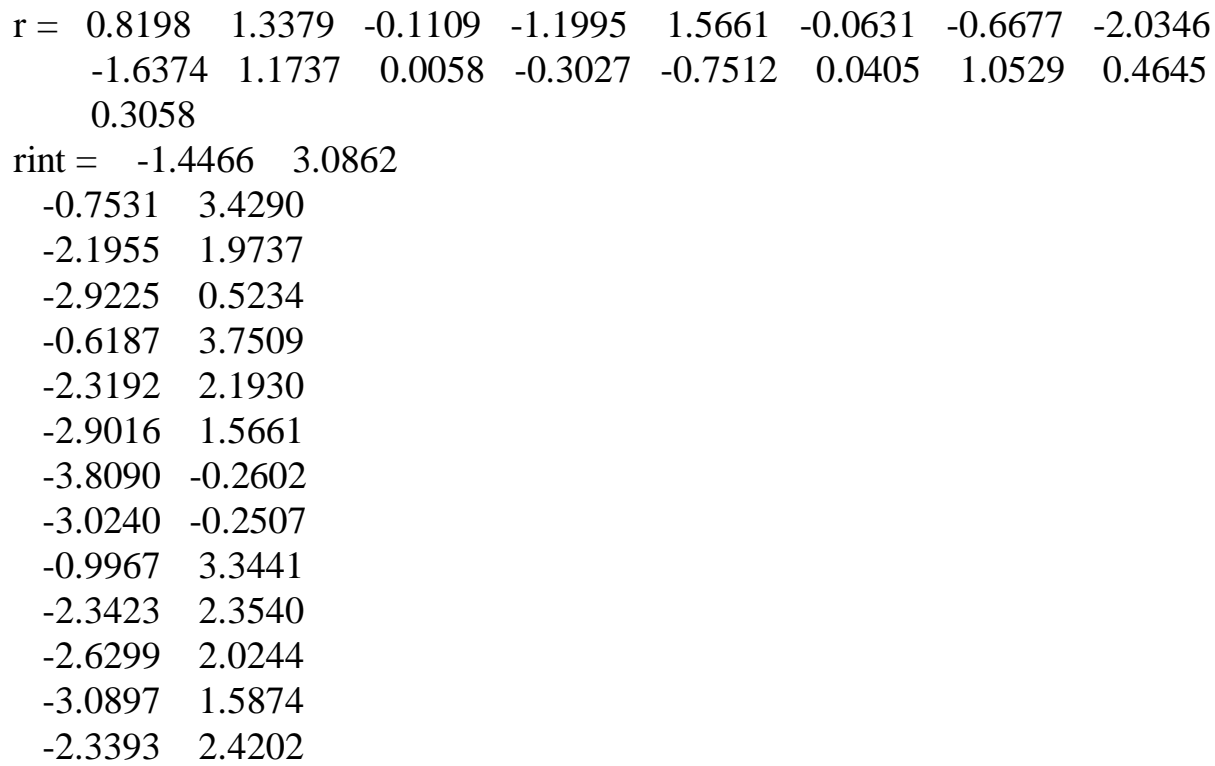


Cristina Bălăceanu, Mihaela Gruiescu, Cristina Coculescu, Oana Camelia Iacob

\section{$-1.2434 \quad 3.3492$}

$-1.8971 \quad 2.8262$

$-2.0158 \quad 2.6274$

In stats is returned: the value of $R^{\wedge} 2$, the value of the $F$ statistic associated with the hypothesis that all the regression coefficients are 0 , respectively the value of significance p, associated with this test [Voineagu, V., Ţiţan, E., Şerban, R. at all, (2007)]:

stats $=\begin{array}{llll}0.7682 & 23.1924 & 0.0000 & 1.2207\end{array}$

Thus, the multiple linear regression model used to model the dependence between the variables analyzed explains the effect variation due to the main variables considered to be $76.82 \%$ and the value $\mathrm{F}=23.1924$ with the significance level of 0.0001 indicates that it is unlikely that all coefficients of the regression polynomial are zero.

>>rcoplot (r,rint)

\section{Figure 6. Residual Case Order Plot}

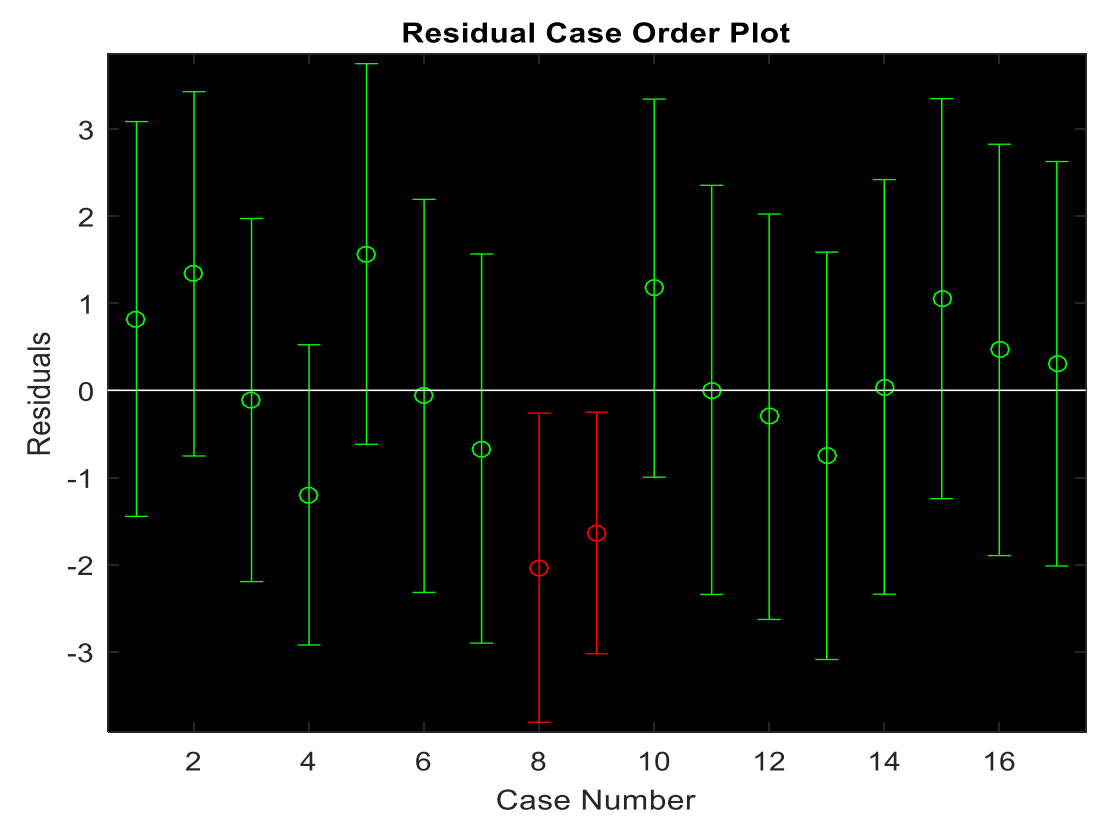

Figure 6 shows graphically the residues calculated with the regress function, together with the reliable intervals, the most acceptable residues being those at which the confidence interval contains 0 [Pieńkowski, J. and P. Berkowitz (2015)].

\section{Conclusions}

In Romania, there is a need for a better adaptability of the educational system to the demands of the labor market, which can be achieved by increasing the level 
of flexibility, sustainable investments in education in the labor force, in the technology of classrooms, changing the points in the curriculum, debating, argumentation, not memorizing, discovery using logical methods based on deduction and then formation of laws, the development of normative-positive binomial to explain and understand the external world, the real life environment, the inclusion of some disciplines to study the reality of the environment businesses still in primary, middle school for the sustainable development of potential workforce). Another point of great interest for the change of educational optics is the reduction of the student groups so that in the classroom they receive attention and support in a unitary way.

The dysfunctions of the educational system have, with time, severe consequences on the evolution of each individual and of all social subsystems. After all, quality education is projected into the potential of an individual to earn income, as well as in the structure of the workforce and in its capacity to generate resources for the construction of GDP and to support social projects.

An indirect link also arises between the ability to perform the education system and the functioning of the pension system in the future. An educational system must generate skill and adaptability in the future workforce, generations of professionals capable of earning sufficient income for their own well-being, but also to support other subsystems and social projects and not a significant number of future social assistants, especially in the difficult and predictable context of the demographic aging of the Romanian population.

Reforming or at least reforming the education system involves both national and international funding, with the European Union creating numerous funds for education and research for member countries, following a rigorous system of competition on research or education projects. And in terms of business development, entrepreneurs employ a workforce capable of generating added value within a shorter timeframe as a result of competition, the rapid pace of development of research products and cutting-edge technologies that surpasses existing technologies by placing the price of newly created down value products with effects on business sustainability.

\section{REFERENCES}

[1] Anderson, Sweeney, Williams, (2008), Statistics for Business and Economics; 10th Edition Revised (Tenth Ed.) 10e, Mason OH by Thomson/SouthWestern;

[2] Andrei, T. (2004), Econometric and Statistics; Economica Publishing House; Bucharest;

[3] Bobko et all. (2005),Work Sample Selection Tests and Expected Reduction in Adverse Impact: A Cautionary Note; International Journal of Selection and Assessment banner https://doi.org/10.1111/j.0965-075X.2005.00295.x;

[4] Breinlich et all. (2015),Distribution of Pd Clusters on Ultrathin, Epitaxial

TiOx Films on Pt3Ti(111); Beilstein Journal of Nanotechnology, volume 6; 
Cristina Bălăceanu, Mihaela Gruiescu, Cristina Coculescu, Oana Camelia Iacob

[5] China Remus et all. (2014), Quality Assurance in Education - A Proactive Approach; Quality access to success; Volume 15, no 139 April 2014, https://search.proquest.com/openview/fe6fa8bccb4363c81da176d843a17442/1?pqorigsite $=$ gscholar $\& \mathrm{cbl}=1046413$;

[6] Coculescu, C., Despa, R. (2011), Quantitative Methods in Economics; Universitara Publishing House, Bucharest;

[7] Enders, W. (1995), Applied Econometric Time Series; J. Wiley, New York; [8] European Comision, (2009),Strategic Framework Education and Traning 2020. Official Journal of the European Union, Brussels, Belgia;

[9] Gaspar Florentina (2018), Approaching the Headmaster in the Context of Current Education Theory; Social Economic Debates, http://www.economicdebates.ro/Art\%2010\%20dse2\%202018Gaspar.pdf;

[10]Gengyuan Liu, Mark T. Brown, Marco Casazza, (2017),Enhancing the Sustainability Narrative through a Deeper Understanding of Sustainable Development Indicators; Sustainability2017, 9(6), 1078; https://doi.org/10.3390/ su9061078;

[11] Gujarati, D.N. (1995), Basic Econometrics; Mc Grow Hill, Int. N.Y., 1995; [12] OECD, (2011),Building a High Quality Teaching Proffesion: Lessons from around the World;OECD Publihing, Paris, France;

[13] Pecican, E.Ş. (2003),Econometric for Economists; Economica Publishing House, Bucharest;

[14] Pieńkowski, J. and P. Berkowitz (2015), Econometric Assessments of Cohesion Policy Growth Effects: How to Make Them More Relevant for Policymakers?; Regional and Urban Policy Regional Working Paper 2015, Jerzy Pieńkowski, Peter Berkowitz*Working Papers: A series of short papers on regional research and indicators produced by the Directorate-General for Regional and Urban PolicyWP 02/2015;

[15] PISA (2015), Results (Volume II): Policies and Practices for Successful Schools; OECD Publishing, Paris, France, www.pisa.oecd.org;

[16] PISA (2015), Results (Volume III), Students' Well-Being http://www.oecd. org/pisa/publications/pisa-2015-results-volume-en.htm;

[17] Rodriguez-Pose, A. and E. Garcilazo (2015),Quality of Government and the Returns of Investment: Examining the Impact of Cohesion Expenditure, in European Regions, Regional Studies 49, 1274-1290;

[18] SABER (2017),www.edupedu.ro;

[19] Vlaston Stefan (2015),PISA 2015 Results. Romania, again in the Tail of Europe, https://adevarul.ro/educatie/scoala/;

[20] Voineagu, V., Ţiţan, E., Şerban, R. at all (2007), Econometrics, Theory and Practice; Meteor Publishing House, Bucharest;

[21]http://ec.europa.eu/eurostat/09.08.2019. 